\title{
Effect of forget instructions with and without the conditions for selective search*
}

\author{
WAYNE SHEBILSKE and WILLIAM EPSTEIN $\dagger$ \\ University of Wisconsin, Madison, Wisconsin 53706
}

\begin{abstract}
A PA probe experiment was conducted to determine whether a mechanism other than selective search is involved in the Only effect of directed forgetting. To accomplish this, a small number of trials which tested all pairs in the list successively ("all" trials) were intermixed with the standard single-probe trials. On "single" trials, both pretest mechanisms and selective search may operate, but on "all" trials, selective search was eliminated. The analysis compared the Only effect and intrusion data under these two conditions and examined the fate of to-be-forgotten (TBF) recall on "all" trials. The evidence confirmed the major role of selective search in producing the Only effect. It was concluded that if a pretest mechanism was operative, it did not have the properties of a voluntary forgetting mechanism and it had only a small effect on the first half of the list.
\end{abstract}

The operation of voluntary control mechanisms has been inferred from the finding that when $S$ is directed to forget part of the innut, recall of to-be-remembered (TBR) material is enhanced relative to recall of the same material when $S$ is required to remember the entire input. This finding has been obtained in a variety of directed forgetting experiments which are reviewed by Epstein (1972). The present study is one of a series of experiments which have used a paired-associate probe task to identify the control mechanisms responsible for the effect of forget instructions (Shebilske, Wilder, \& Epstein, 1971; Epstein, Massaro, \& Wilder, 1972; Epstein \& Wilder, 1972). The prototypical trial in the paired-associate probe experiment proceeds as follows: the first set of pairs is presented, one at a time, then an interset interval, a second set of pairs, is presented, followed immediately by a briefly exposed cue ("only first," "only second," or "either") which specifies S's memory load for the trial, then a short retention interval culminating in a probe for one of the pairs. Superior recall on "only" trials relative to "either" trials defines the Only effect. Inasmuch as the cue follows the input, the effect of forget instructions is limited to retrieval processes occurring at the time of the test and to pretest processes occurring in the short retention interval between the cue and test.

\section{RETRIEVAL PROCESSES}

A forget cue could operate during retrieval to reduce the number of response alternatives. This could be accomplished by a selective search mechanism which directs attention exclusively to TBR material. Limiting

*This research was partially supported by Research Grant MH 20584-01 from the National Institute of Mental Health, United States Public Health Service. The authors wish to thank Lucinda Wilder and Donald Homa for valuable discussion of this work.

$†$ Requests for reprints should be sent to William Epstein, Department of Psychology, Charter at Johnson Street, University of Wisconsin, Madison, Wisconsin 53706. the number of alternatives could facilitate both search and decision retrieval processes. There is considerable evidence that selective search is involved. Epstein, Massaro, and Wilder (1972) have shown that recall is unaffected by forget instructions when the search sets on "only" (forget) and "either" (nonforget) trials are equated in size and composition. In addition, Epstein and Wilder (1972) have found that the likelihood of correctly recalling a to-be-forgotten (TBF) item depended on the locus of S's search. Although these studies show that selective search plays an important role in determining the Only effect, they do not eliminate the possibility that forget instructions cause a change in memory strengths in favor of TBR material during the retention interval.

\section{PRETEST PROCESSES}

One pretest process which might be affected by forget instructions is conscious rehearsal. When no forget instruction is given, $\mathrm{S}$ may rehearse the whole list, but when a forget instruction is given, $S$ may selectively rehearse the TBR set. The increased rehearsal of the TBR set would enhance its memory strength, thereby accounting for the Only effect. However, Shebilske et al (1971) and Epstein, Massaro, and Wilder (1972) found that the magnitude of the Only effect was virtually the same with and without the opportunity for selective rehearsal. Therefore, it can be concluded that selective rehearsal is not a major determinant of the Only effect in the probe paradigm.

Conscious rehearsal is not the only mechanism which could operate during the retention interval on forget trials. When a forget cue is given, S may employ a mechanism which operates in a way similar to an erasure mechanism in digital computers. By means of this mechanism, $S$ may voluntarily forget TBF material. To be consistent with the results of Shebilske et al (1971) and Epstein, Massaro, and Wilder (1972), it would have to be assumed that the operation of this voluntary forgetting mechanism is equally effective with or 
without the opportunity for conscious rehearsal. Voluntary forgetting could account for the Only effect, since reducing the memory strength of TBF material could reduce its interference potential, thereby enhancing TBR recall.

Some studies have reported performance on TBF material, but not under conditions which allow voluntary forgetting to be assessed independently of other influences. For example, Davis and Okada (1971) found lower recognition and recall of TBF material. However, in their procedure, Ss could selectively rehearse for about $1 \mathrm{sec}$ after each presentation of 64 items. Under these conditions, selective rehearsal is probably primarily responsible for any differences between TBR and TBF performance. Other studies (Block, 1971; Elmes, Adams, \& Roediger, 1970) reported no difference in recognition of TBR and TBF material, arguing for equal availability of TBR and TBF items. On the other hand, there is evidence that TBF material is not recalled as well as TBR material (Epstein, 1969; Epstein \& Wilder, 1972; Reitman, Malin, Tanner, Bjork, \& Higman, 1971). However, in each of these studies, the results may be attributed to more than one process (e.g., rehearsal or retrieval) and therefore are difficult to interpret with respect to voluntary forgetting.

The principal aim of the present study was to determine whether a pretest mechanism similar in its effect to voluntary forgetting would be observed to operate under conditions that precluded the operation of the two potential alternative responses to forget instructions, i.e., selective rehearsal and selective search. Although the evidence of our previous experiments with the present paradigm shows that selective rehearsal is not responsible for the Only effect, the precaution was adopted of filling the retention interval with a distractor task which preempted conscious rehearsal. In order to eliminate selective search, a new type of test was designed and included along with the standard single-pair tests. These new tests which occurred infrequently, and were not designated in advance, solicited recall of all pairs in the list by probing successively for each response in random order. Consider the case of an "only" cue which is followed by the first probe, color-coded to inform $S$ that it is the first probe of an all-test trial. If the "only" cue (remember only first, or remember only second set) has triggered a voluntary forgetting mechanism during the present period, then the cue should confer an advantage in recall on this test, as well as on the standard single-test trial. However, if pretest processes are not involved in the Only effect, then the cue effects should be absent on all tests. The Only effect will be absent because selective search is absent. Since $S$ has been informed that all pairs will be probed, he cannot restrict his search to any subset of pairs, and there will be no difference in the size or composition of the search set following "either" and "only" cues. Therefore, the presence of an Only effect on "all" tests, as well as on "single" tests, will be taken as evidence of the effect of pretest voluntary forgetting; the absence of an Only effect on "all" tests will suggest that the emphasis we have placed on selective search in our earlier accounts need not be modified to include consideration of pretest processes. In addition to the proportion correct data, the error data can also help decide the question. If voluntary forgetting is operative, then recall of TBF material following an "only" cue on all-test trials should be lower than recall of the same material on an "all" test that follows an "either" cue. Furthermore, there should be a reduction of intrusions from the TBF set following "only" cues relative to comparable material following "either" cues.

\section{METHOD}

\section{Subjects}

The 88 Ss were undergraduate and graduate students who were paid volunteers or who participated to fulfill a course requirement. These $S$ s indicated on a postexperimental questionnaire that they did not change their learning strategy in any way after the introduction of "all" trials. Fifteen other Ss were discarded and replaced because they reported a strategy change.

\section{Materials and Apparatus}

Slides of 160 pairs were prepared and presented by means of a Kodak projector. A Psionix Series 1600 logic system controlled the presentation rate.

The stimuli were CVC nonsense syllables selected from the Archer (1960) norms (range, 37-61). An attempt was made to include an equal number of syllables beginning with each consonant and to minimize visual and acoustic similarity. The responses were chosen from categorized lists of common English words prepared by Battig and Montague (1969). Four words were selected from each of 36 categories for use in the experimental lists. Two words were selected from each of 8 additional categories for use in the practice lists. The highest-frequency words within a category which were not given as responses for another category and were between three and six letters long were chosen. Syllables and words were randomly paired with the restriction that words within a given category were paired with syllables having different first letters and that visual and acoustic similarity within the pairs were avoided. Subtraction problems, two digits minus one digit, served as the filler task.

\section{Procedure}

The Ss were not informed about "all" trials until they had 16 "single" trials. Following the initial instructions which only mentioned "single" trials, Ss had 4 practice, 4 dummy, and 8 experimental "single" trials. During the 4 practice trials, E told Ss exactly what to do and observed the Ss to insure that they understood the task.

The dummy trials were identical to experimental "single" trials from S's point of view; however, the data from these trials were not analyzed and items were not counterbalanced over dummy trials. They were included to reduce warm-up effects.

After the "all" instruction, there were 10 dummy "single" trials, 8 experimental "single" trials, and 6 "all" trials. The dummy trials were included to maintain a low ratio of "all" to "single" trials. Four dummy trials had the cue "first," 4 had the cue "second," and 2 had the cue "either." The trial number of 
"all," "single," and dummy trials always remained the same. Trials 17-40 occurred after the "all" instructions. The "all" trials were Trials $20,27,29,34,38$, and 40 . The experimental "single" trials were $24,25,26,31,32,33,36$, and 37 . The remainder were dummy trials. The particular cue and serial position tested on a given experimental "single" trial or "all" trial were in a different random order for each S block.

Each list was presented as follows: after a 2-sec ready signal, two pairs were presented one at a time, a subtraction-classification problem appeared, two more pairs were presented one at a time, then there was a .10-sec exposure of the cue, another subtraction-classification problem appeared, and finally a test slide was presented. The pairs were presented for $2 \mathrm{sec}$ each and the filler problems for $3 \mathrm{sec}$ each. The test was presented for $7 \mathrm{sec}$, and a 3 -sec interval preceded the next ready signal. On "all" trials, four test slides were presented for $7 \mathrm{sec}$ each. The material was presented on a blue background, except for the four "all" test slides. In order to distinguish these, they were presented on a green background and the word "all" was printed on the top of the slide.

The recorded instructions explained the cues as follows: "The word 'first' indicates that the tested pair will come from the first set of two pairs. Therefore, you can forget the second set because it will not be tested. The word 'second' indicates that the tested pair will come from the second set of two pairs. Therefore, you can forget the first set because it will not be tested. The word 'either' indicates that the tested pair will come from either the first or second set of pairs." It was emphasized that the cues would always describe the test accurately and that a given pair would be presented only once. The Ss were also told that the lists were structured in such a way that the first two PAs contained words from the same category and the second two PAs contained words from a different category: for example, MEK-GOLD, BYN-STEEL, GIF-MILK, SAC-COFFEE. The Ss were also told that when a subtraction problem appeared, they should write the answer to the problem and write " $O$ " if the answer was an odd number and " $E$ " if the answer was an even number. The Ss were urged to answer and classify all subtraction problems correctly, but they were also told not to spend any learning or recall time on subtraction.

The "all" instructions were read to the S after the 16 th trial. They emphasized the importance of maintaining the same learning strategy. They were in part: "In the rest of the experiment there will be a few 'all' trials; their purpose is to let us compare what happens to pairs you are trying to remember with pairs you were told to forget. If an 'all' nonsense syllable occurs and you remember the word that goes with it. fine. write it down. The most important thing. though. is to keep on doing just what you have been doing up to now. When the cue is 'first' or 'second' remember the cued set and forget the pairs that will not be tested." The "all" instructions also told Ss how they could distinguish an "all" test slide from the others and that all four pairs would be presented in a haphazard order bearing no relationship to the cue or input order.

Two Ss were run during each 1-h session. The Ss wrote their responses in a booklet. After each word response. Ss turned the page so that previous responses were not visible. On "all" trials. the four responses were also written on separate pages. The $S$ s were not allowed to change or make additions to previous responses. If the Ss did not know a response. they were free to guess or to write a question mark on the page. At the conclusion of the experiment, the Ss were given a questionnaire concerning their learning strategy.

\section{Design}

The instruction cue defined different memory sits. For a given list. the instruction cue was the word "first." "second." or "either." The word "first" indicated that the tested pair would be one of the first two pairs, and the word "second" indicated that the tested pair would be one of the second two pairs. These were "only" cues in that only the TBR set was tested on most of the trials. The cue "either" indicated that any one of the four pairs would be tested. On "single" trials, when an "only" cue was given, only the TBR set was tested. When an "either" cue was given, the tested item belonged to a memory set which will be called the "either" set. Both the TBR and "either" set were tested at all four serial positions. These eight set-position combinations were tested once before the Ss were told about "all" trials and again after "all" trials were introduced.

When an "only" cue was given on an "all" trial, pairs were tested from both the TBR and TBF memory sets. Of course, when an "either" cue was given, all the items belonged to the "either" set. The three memory sets, TBR, TBF, and "either," were tested equally of ten in each ordinal position. However, in order to maintain a low ratio of "all" to "single" trials, only half of the input list was tested for each $S$ in the first test position on "all" trials. Input Positions 1 and 3 were tested for one group of Ss and 2 and 4 were tested for another group of Ss. The critical input positions for each group were always tested in Ordinal Positions 1 and 4 . The other serial positions for each group were always tested in Ordinal Positions 2 and 3. To make this possible, serial positions were always tested in the order $1,4,2$, 3 or 3,2, 4,1 for Group 1 and the order $2,3,1,4$ or $4,1,3,2$ for Group 2. The Ss were told that there was no pattern, i.e., that all four pairs would be tested in a haphazard order, and postexperimental interrogation indicated that Ss were not aware of the pattern.

The experiment was designed to allow three analyses of variance. One, which included the performance of the two groups on "single" trials, had the following within-S variables: memory set (TBR or "either"), serial position of input list (1 through 4), and replication (before or after the "all" instruction). The second analysis compared performance on "single" trials after the "all" instructions with performance on TBR and "either" material in the first test position of "all" trials. In this analysis, only the data from the critical positions from the two groups were analyzed. The third analysis, which included the two groups on "all" trials, had the following within-S variables: memory set (TBR, TBF, or "either"), serial position of input list (first half or second half), and ordinal position of "all" tests ( 1 through 4).

In order to accomplish the appropriate counterbalancing. $22 \mathrm{~S}$ blocks were run for each group with two $S$ s in each block. Items were counterbalanced for any comparison within "single" trials. Items were balanced only for the critical input positions in each group for comparisons between "single" and "all" trials or within "all" trials.

\section{RESULTS}

Figure 1 provides a graphic summary of the most critical recall data. The correct response proportions are shown in Fig. 1 as a function of memory set and serial position for "single" trials which occurred before and after the introduction of "all" trials and for the first ordinal position of "all" trials. The magnitude of the Only effect for each trial type can be evaluated by comparing the data points for the TBR memory set (circles) and the "either" memory set (squares). The amount of forgetting of TBF material can be seen by comparing the data points for the TBF memory set (triangles) with the "either" memory set which 


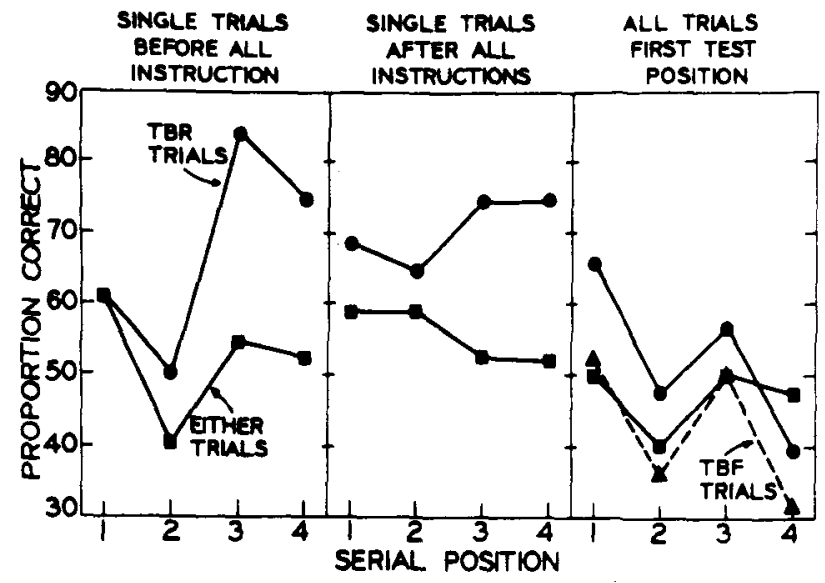

Fig. 1. Proportion correct on "single" trials and the first test position of "all" trials for the three memory sets (TBR; "either" on "single" trials; and TBR, "either," and TBF on "all" trials) as a function of input serial position.

represents comparable material on nonforget trials.

Statistical analyses will be presented separately for comparisons within "single" trials and "all" trials and for comparisons within "all" trials. Also, intrusion data for "single" and "all" trials will be presented.

\section{"Single" Trials}

The correct response proportions on "single" trials are shown in Table 1 as a function of memory set, serial position, and group. The groups are distinguished by the serial positions which were tested in the first ordinal position of "all" trials. The data from the corresponding serial positions on "single" trials are italicized in Table 1 . In order to provide the most powerful test of the assumption that the introduction of "all" trials did not cause a change in learning strategy, every serial position was analyzed for comparisons within "single" trials. An analysis of variance supported the assumption that the Only effect was unaffected by the introduction of "all" trials. Recall of the TBR memory set (.689) was significantly higher than recall of the "either" memory set $(.527)[F(1,86)=41.74, p<.001]$, and the before and after "all"-trials variable did not interact with memory set or any other variable. The analysis also showed that performance after the introduction of "all" trials (.636) was significantly higher than performance before the introduction of "all" trials $(.580)[F(1,86)=$ $4.90, \mathrm{p}<.05]$. This probably reflects a general practice effect.

\section{"Single" vs "All" Trials}

An analysis of variance compared TBR and "either" memory sets for the first ordinal position of "all" trials and "single" trials which occurred after the introduction of "all" trials. These subsets of the "all" and "single" data were chosen because they were considered the most comparable. References to "all" and "single" trials in this section denote only these subsets. The analysis showed that overall performance was significantly higher on "single" trials (.631) than on "all" trials (.503) $[F(1,86)=12.96, p<.01]$ and that TBR performance (.622) was significantly higher than "either" performance $(.511)[\mathrm{F}(1,86)=8.41, \mathrm{p}<.01]$. Although trial types and memory set did not show a significant interaction $[F(1,86)=1.73, p>.05]$, *a planned comparison showed that recall of the TBR set was significantly lower on "all" trials (.534) than on "single" trials $(.710)[F(1,86)=11.50, p<.05]$, while recall of "either" set was not significantly lower on "all" trials (.472) than on "single" trials $(.551)[\mathrm{F}(1,86)=2.32$, $p>.05]$. These planned comparisons contradict the main analysis which shows no significant interaction and suggests that the Only effect on "all" trials (.062) is reliably smaller than the Only effect on "single" trials (.159). The only interaction that was significant was that of Memory Set by Trial Type by Half of Input List $[F(1,86)=5.34, p<.05]$. Subsequent tests showed that the Only effect did not differ significantly on "single" and "all" trials in the first half of the list $[F(1,86)<1]$, whereas the Only effect was significantly reduced on "all" trials in the second half of the list $[F(1,86)=8.12$, $p<.01\}$. On "all" trials, the Only effect on the first half of the list $(.113)$ was significant $[F(1,86)=3.98$, $p<.05$ ], while the Only effect on the second half of the list $(.011)$ was not significant $[F(1,86)<1]$. In addition, on the first half of the list, "either" performance on "all" trials (.455) was significantly lower than "either" performance on "single" (.591) trials $[F(1,86)=5.76, p<.05]$. In the second half of the list, "either" performance was not significantly

Table 1

Proportion of Correct Responses on "Single" Trials as a Function of Memory Set, Serial Position, and Replication for Groups 1 and 2

\begin{tabular}{|c|c|c|c|c|c|c|c|c|c|}
\hline \multirow[b]{2}{*}{ Cue } & & \multicolumn{4}{|c|}{$\begin{array}{c}\text { Pre "All" Instructions } \\
\text { Serial Position }\end{array}$} & \multicolumn{4}{|c|}{$\begin{array}{c}\text { Post "All" Instructions } \\
\text { Serial Position }\end{array}$} \\
\hline & & 1 & 2 & 3 & 4 & 1 & 2 & 3 & 4 \\
\hline Group 1 & $\begin{array}{l}\text { TBR } \\
\text { Either }\end{array}$ & $\begin{array}{l}.614^{*} \\
.614\end{array}$ & $\begin{array}{l}.614 \\
.455\end{array}$ & $\begin{array}{l}.818 \\
.545\end{array}$ & $\begin{array}{l}.614 \\
.477\end{array}$ & $\begin{array}{l}.682 \\
.591\end{array}$ & $\begin{array}{l}.591 \\
.455\end{array}$ & $\begin{array}{l}.750 \\
.523\end{array}$ & $\begin{array}{l}.795 \\
.636\end{array}$ \\
\hline Group 2 & $\begin{array}{l}\text { TBR } \\
\text { Either }\end{array}$ & $\begin{array}{l}.659 \\
.545\end{array}$ & $\begin{array}{l}.500 \\
.409\end{array}$ & $\begin{array}{l}.705 \\
.432\end{array}$ & $\begin{array}{l}.750 \\
.523\end{array}$ & $\begin{array}{l}.682 \\
.614\end{array}$ & $\begin{array}{l}.659 \\
.591\end{array}$ & $\begin{array}{l}.841 \\
.523\end{array}$ & $\begin{array}{l}.750 \\
.500\end{array}$ \\
\hline
\end{tabular}

*The italicized scores are shown in Fig. 1 . 
Table 2

Proportion of Correct Responses on "All" Trials as a Function of Memory Set, Serial Input Position, and Test Position

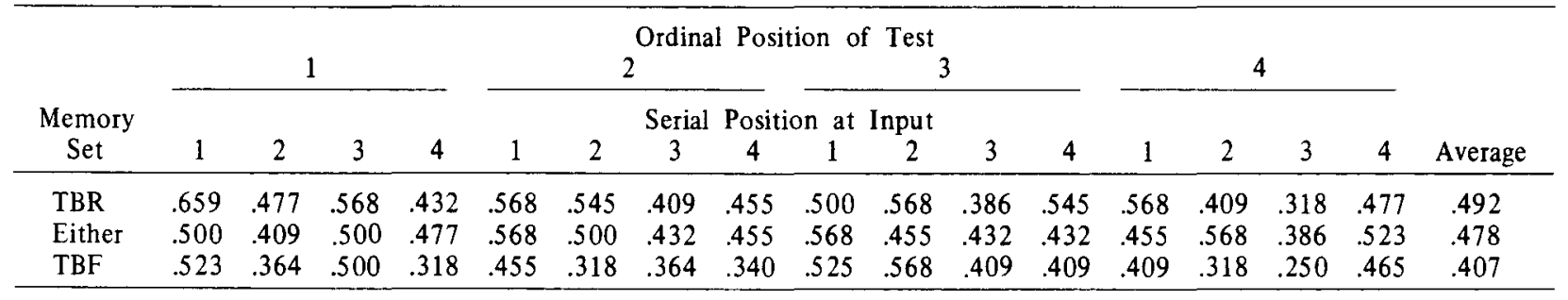

different on "single" (.511) and "all" (.489) trials $[\mathrm{F}(1,86)<1]$.

\section{“All” Trials}

Table 2 shows the proportion of correct responses on "all" trials as a function of memory set, serial position of the input, and ordinal position of the test. The data from the last three ordinal positions are presented for completeness. The data from these positions are confounded with increased retention interval and previous response attempts. Therefore, the analysis of them will not be presented. ${ }^{1}$

The results from the first ordinal position of "all" trials was analyzed separately primarily to evaluate TBF performance. For the first ordinal test position, the averages for the first half of the input list were .568 , .455 , and .443 for the TBR, "either," and TBF memory sets, respectively. For the second half of the list, the comparable averages were $.500, .489$, and .409 . The difference between "either" and TBF was not significant for either part of the list $[F(1,516)<1$, and $F(1,516)=$ $2.80, p>.05]$. Consistent with the previous analyses, the difference between TBR and "either" performance was significant $[F(1,516)=5.83, p<.05]$ for the first half of the list and not significant $[F(1.516)<1]$ for the second half of the list.

\section{Intrusion Data}

Table 3 shows the proportion of intralist intrusions which were members of the TBR and TBF memory sets as a function of trial type. With an "either" cue, S was responsible for both sets and the labels TBR and TBF correspond to the tested and not-tested sets, respectively. There was a greater opportunity for $T B F$ intrusion because there were two untested TBF items and only one untested TBR item. To correct for differential opportunity, Table 3 presents the intrusion rate per item which was obtained by substituting the mean for the total number of intrusions. On "single" trials, the proportion of TBF intrusions was lower when a forget cue was given (TBR set tested) than when $S$ was responsible for the whole list ("either" set tested). On "all" trials, the proportion of TBF intrusions was approximately half for all memory sets which were tested. This was true for the first ordinal test position as well as for the average of all four ordinal positions.

\section{DISCUSSION}

Since we intend to use the comparison between "single" and "all" as a basis for inferences about the role of pretest processes in producing the Only effect on the standard "single" trial, we must establish that (a) pretest processing was the same on "all" trials and "single" trials that followed introduction of "all" instructions, and (b) that pretest processing was not modified by introduction of "all" instructions. The first condition may be safely assumed on the grounds that there were no cues to allow $S$ to distinguish "single" from "all" trials in advance of the test. We sought to insure the second condition by providing training on the standard probe task before mentioning the "all" trials, by maintaining a low ratio of "all" to "single" trials, by encouraging Ss not to change their processing strategy in anticipation of.the few "all" trials, and by replacing Ss who reported a change in strategy. The training trials also provided an internal check for changes in strategy.

Table 3

Proportion of Intralist Intrusions that Were Members of the TBR and TBF Memory Sets

\begin{tabular}{|c|c|c|c|c|c|c|c|c|c|c|}
\hline \multirow{3}{*}{$\begin{array}{l}\text { Intru- } \\
\text { sion } \\
\text { Set } \\
\end{array}$} & \multicolumn{4}{|c|}{ Single Trials } & \multicolumn{6}{|c|}{ All Trials } \\
\hline & \multicolumn{2}{|c|}{$\begin{array}{l}\text { Before "All" } \\
\text { Introduction } \\
\text { Tested Set } \\
\end{array}$} & \multicolumn{2}{|c|}{$\begin{array}{l}\text { After "All" } \\
\text { Introduction } \\
\text { Tested Set } \\
\end{array}$} & \multicolumn{3}{|c|}{$\begin{array}{c}\text { First } \\
\text { Ordinal Position } \\
\text { Tested Set }\end{array}$} & \multicolumn{3}{|c|}{$\begin{array}{c}\text { All Four } \\
\text { Ordinal Positions } \\
\text { Tested Set }\end{array}$} \\
\hline & $\mathrm{TBR}$ & Either & TBR & Either & TBR & TBR & Either & TBR & TBF & Either \\
\hline $\begin{array}{l}\text { TBR } \\
\text { TBF } \\
\end{array}$ & $\begin{array}{l}.76^{*} \\
.24 \\
\end{array}$ & $\begin{array}{l}.57 \\
.43 \\
\end{array}$ & $\begin{array}{l}.85 \\
.15 \\
\end{array}$ & $\begin{array}{l}.58 \\
.42 \\
\end{array}$ & $\begin{array}{l}.50 \\
.50 \\
\end{array}$ & $\begin{array}{l}.53 \\
.57 \\
\end{array}$ & $\begin{array}{l}.58 \\
.42 \\
\end{array}$ & $\begin{array}{l}.52 \\
.48\end{array}$ & $\begin{array}{l}.48 \\
.52 \\
\end{array}$ & $\begin{array}{l}.52 \\
.48\end{array}$ \\
\hline
\end{tabular}

*These scores represent the intrusion rate per item. 
Such changes would be reflected in a comparison of "single" trials before and after the introduction of "all" trials. The fact that comparisons of "single" trials before and after the introduction of "all" trials showed no interactions with memory set or any other variable supports the claim that pretest processing was not affected by the introduction of the all-test instructions. Taken together with the first conclusion, we have sufficient grounds for inferring that pretest processing on "single" and "all" trials was identical.

The theoretical significance of the comparison between recall on "single" and "all" tests rests on the assumption that selective search of the set containing the tested pair was not possible on the "all" test. This assumption is reasonable on procedural considerations, and the Ss' postexperimental reports support this assumption. Additional support is provided by the intrusion data. If items from the TBF set are eliminated as response alternatives, then one would expect a reduction in TBF intrusions on "only" trials. However, as Table 3 shows, this tendency which was obvious on "single" trials was completely absent on "all" trials. Therefore, we may infer that selective search was absent on "all" trials.

Based on the preceding arguments, it is concluded that the present procedure allows an independent assessment of voluntary forgetting and selective search in the standard probe paradigm. Our assessment will be based exclusively on an examination of performance on "single" trials following introduction of the "all" instructions and performance on the first test position of the "all" trials. Performance on subsequent tests on the "all" trials cannot be compared confidently with "single" trials because the subsequent tests were influenced by prior tests and increased retention intervals.

The results from the second half of the list will be considered first. On "single" trials when the cue "second" was given, a large Only effect was obtained (Positions 3 and 4 in center panel of Fig. 1), replicating the results of previous experiments (e.g., Shebilske et al, 1971; Epstein et al, 1972). On "all" trials in the second half of the list (Positions 3 and 4 in right-hand panel of Fig. 1), there was a nonsignificant $2 \%$ drop in "either" recall and a significant $25 \%$ drop in TBR recall relative to the "single" trials, resulting in virtual elimination of the Only effect. Furthermore, when the cue "second" was given on "all" trials, recall of the TBF items in the first half of the list was approximately equal to "either" recall. In summary, on "all" trials, when the cue "second" was given, TBR, TBF, and "either" recall did not differ.

An advocate of the voluntary forgetting hypothesis might attempt to explain the absence of an Only effect by supposing that, although pretest processes caused a difference in memory strength on forget trials, these differences were cancelled by the effects of output interference. On "all" trials, all four pairs were tested. Consequently, during the first test on "all" trials, Ss may have recycled the other three items in preparation for subsequent tests. If conditions were such that more items were recycled on some trials than on others, we could expect an advantage in favor of the latter. However, it is unlikely that recycling influenced recall differentially for the TBR, TBF, and "either" memory sets, since Ss had to recycle three items no matter what cue was given. Therefore, we may reject the cancellation explanation of the failure to observe an Only effect and lower TBF recall. We conclude that when Ss are directed to forget the first half of the list, memory strength is not affected by a voluntary forgetting mechanism or by any other pretest mechanism. Consequently, it may be inferred that selective search is the sole contributor to the Only effect in the second half of the list in the standard probe paradigm.

Although there is no evidence for pretest effects of instructions when Ss are directed to forget the first half of the list, there are indications that memory strength may have been affected when Ss were directed to forget the second half of the list. When the cue "first" was given on "all" trials, recall of TBR items was $11 \%$ higher than recall of "either" items in the first half of the list and recall of TBF items was $8 \%$ lower than recall of "either" items in the second half of the list. Following our logic, these results would implicate the effect of instructions on pretest processing. However, the level of "either" recall in the first half of the list weakens the argument. "Either" recall was significantly lower on "all" trials than it was for the first half of the list on "single" trials. The Only effect in the first half on "all" trials seems to have resulted from an unexplained drop in "either" recall rather than from an enhancement of TBR recall as the result of pretest processes. Put differently, if "either" recall in the first half of the list on "all" trials had been at the level of "either" recall for the first half of the list on "single" trials, as was true for the second half of the list, then TBR (only) recall and "either" recall would have been equivalent and an Only effect would not have been observed in the first half on "all" trials.

Moreover, if a pretest mechanism is at work in the first half of the list, it is unlikely to have the properties of voluntary forgetting. The hypothesis of voluntary forgetting assumes that there is a generalization gradient of associations between a stimulus and each response in the list and that a forget cue enhances TBR recall by reducing the probability of TBF retrieval given a TBR stimulus. Accordingly, one would expect a reduction in TBR intrusions. This reduction is typically obtained; however, on the "all" trials, when selective search was eliminated, TBF and TBR intrusions were equal. This does not rule out the possibility that some other pretest mechanism differentially affects memory strength. However, if some pretest mechanism operates, it has only a small effect which is confined to the first half of the list. It can be concluded that selective search is the major determinant of the Only effect in the probe paradigm. 


\section{REFERENCES}

Archer, E. J. A re-evaluation of the meaningfulness of all possible CVC trigrams. Psychological Monographs, 1960, 74(No. 10 ).

Battig, W.. \& Montague, W. E. Category norms for verbal items in 56 categories: A replication and extension of the Connecticut category norms. Journal of Experimental Psychology, Monograph, 1969, 80(3, Pt. 2).

Block. R. A. The effects of instructions to forget in short-term memory. Journal of Experimental Psychology, 1971, 89, 1-9.

Davis, J. C., \& Okada, R. Recognition and recall of positively forgotten items. Journal of Experimental Psychology, 1971, $89,181-186$.

Elmes, D. G., Adams, C., \& Roediger, H. L. Cued forgetting in short-term memory. Journal of Experimental Psychology, 1970, 86, 103-107.

Epstein, W. Postinput output specification and differential retrieval from short-term memory. Journal of Experimental Psychology, 1969, 82, 168-174.

Epstein, W. Mechanisms of directed forgetting. In G. Bower (Ed.), The psychology of learning and motivation. Vol. 6
New York: Academic Press, 1972.

Epstein, W., Massaro, D. W., \& Wilder, L. Selective search in directed forgetting. Journal of Experimental Psychology, $1972,94,18-24$

Epstein, W., \& Wilder. L. Searching for to-be-forgotten material in a directed forgetting task. Journal of Experimental Psychology, 1972, 95, 349-357.

Reitman, W. R., Malin, J. T., Tanner, J. E., Bjork, R. A., \& Higman, B. Strategy control in directed forgetting. Mental Health Research Institute Communication No. 284, 1971, University of Michigan, Ann Arbor.

Shebilske, W., Wilder, L., \& Epstein, W. Forget instructions: The effect of selective rehearsal and categorical distinctiveness. Journal of Experimental Psychology, 1971, 89, 372-378.

\section{NOTE}

1. Details of this analysis can be obtained upon request.

(Received for publication February 6, 1973; accepted February 12, 1973.) 